\title{
Youssef's syndrome following caesarean section: a rare case with review of literature
}

\author{
Vikas Devkare ${ }^{1}$, Meenakshi Gothwal'², Nandkishor Gaikwad ${ }^{1}$, Sushil Pawar ${ }^{1}$, \\ Neha Agrawal ${ }^{1}$, Ashwini Desai ${ }^{1}$
}

\begin{abstract}
${ }^{1}$ Department of Obstetrics and Gynecology, Government Medical College, Miraj, Maharashtra, India
${ }^{2}$ Department of Obstetrics and Gynecology, All India Institute of Medical Sciences, Jodhpur, Rajasthan, India
\end{abstract}

Received: 13 September 2018

Accepted: 06 October 2018

*Correspondence:

Dr. Meenakshi Gothwal,

E-mail: meenakshigothwal@gmail.com

Copyright: ( $)$ the author(s), publisher and licensee Medip Academy. This is an open-access article distributed under the terms of the Creative Commons Attribution Non-Commercial License, which permits unrestricted non-commercial use, distribution, and reproduction in any medium, provided the original work is properly cited.

\begin{abstract}
Youssef's syndrome is a rare condition characterized by vesicouterine fistula with cyclic haematuria, amenorrhoea and incontinence of urine. A vesicouterine fistula is an abnormal connection between the uterus and bladder that most commonly occur due to inadvertent injury to the bladder during lower segment caesarean section. Vesicouterine fistula leads to psychological and has the negative impact on quality of life. A high suspicion should be kept in mind if the patient presents with urinary incontinence even many years after caesarean section. However, conservative management may be appropriate in some cases, but the definitive mode of management is surgery. Hereby authors present a 22-year-old para 2 live 2 (previous 2 caesarean section) with vesicouterine fistula with the complaint of urinary incontinence, cyclical haematuria (menouria) and amenorrhoea a year after caesarean section done due to obstructed labour.
\end{abstract}

Keywords: Menouria, Urinary incontinence, Vesicouterine fistula, Youssef syndrome

\section{INTRODUCTION}

Vesicouterine fistula (VUF) is a rare urogenital fistula. VUF is an abnormal communication that occurs between the bladder and the uterus. ${ }^{1,2}$ Only few cases reported in the literature. Kinpe and colleagues in 1908 reported the first case of VUF. $^{3}$ It is named after the Egyptian gynaecologist Abdel Fattah Youssef. Youssef in 1957 described the vesicouterine fistula with classical triad of urinary incontinence, cyclic haematuria (menouria) and amenorrhoea. ${ }^{4}$ In $83-85 \%$ of cases, iatrogenic injury especially during Lower caesarean section accounts the cause of VUF. Repeated caesarean section doubles the risk of VUF. ${ }^{3}$ Other less common causes of VUF are dilatation and curettage, uterine rupture, placenta percreta, instrumental delivery, manual removal of placenta, obstructed labor. Other least frequent causes are migrated intrauterine contraceptive device, brachytherapy, inflammatory bowel disease, endometriosis, bladder tuberculosis and congenital lesions. ${ }^{3,4}$ Diagnosis of VUF is quiet challenging. Various methods are available that includes methylene blue test, cystoscopy, a retrograde cystography; hysterosalpingography contrast enhanced computed tomography, and Magnetic resonance imaging. ${ }^{5}$

However, conservative management may be appropriate in some cases, but the definitive mode of management is surgery. Various approaches followed for surgery like open transabdominal, laparoscopic, robot assisted laparoscopic repair. ${ }^{3}$ Hereby authors present a 22 -yearold para 2 live 2 (previous 2 caesarean section) with vesicouterine fistula with complain of urinary incontinence, cyclical haematuria (menouria) and amenorrhoea a year after caesarean section done due to obstructed labor. 


\section{CASE REPORT}

Mrs XX, P2L2, 22-year-old Hindu female reported to our institute with chief complain of cyclic bleeding per urethra along with urinary incontinence from past 6 month. Patient is lactating and ammenorrhic from past 1year. Patient was apparently well 6-month back then she complained of pain abdomen with cyclic bleeding per urethra and dribbling of urine per vagina. Patient had two lower segment caesarean section with first caesarean done 3 years back for fetal distress. She underwent second caesarean 1 year back for obstructed labor. Patient gave history of prolong catheterisation of approximately 21 days after second caesarean section.

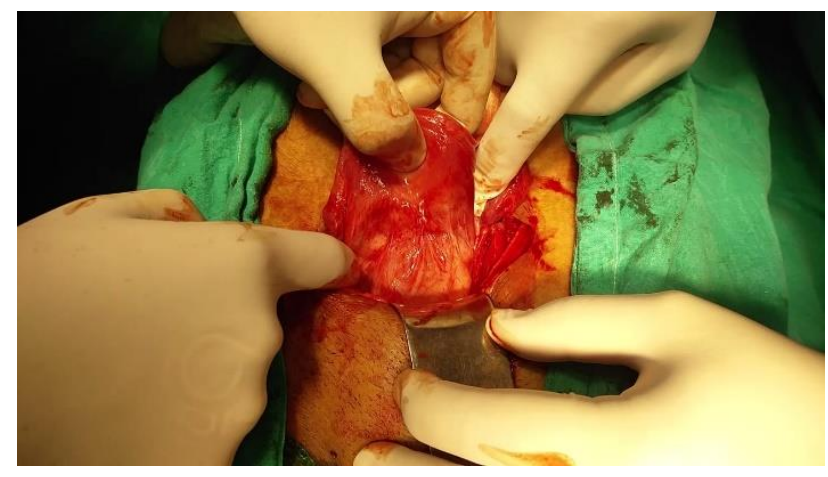

Figure 1: Dense adhesion between the posterior wall of the bladder and anterior wall of the uterus.

On examination general condition was satisfactory, per abdomen was soft. Healthy pfannesteil scar was there. Noticeable urine smell was there during examination. On per speculum examination, cervix seems to be healthy. No urine leak seen during the speculum examination. Per vaginal examination seems to be normal. The biochemical, haematological and hormonal investigations were normal. Abdominal sonography done that was suggestive of VUF. Patient planned for hysterocystoscopy under anaesthesia. The cystoscopy and hysteroscopy suggestive of $2 \mathrm{~cm}$ fistulous opening on posterior wall of bladder with irregular congested margins; a guide wire passed through this opening and visualized hysteroscopically through anterior wall of uterus. The endometrium was thin Diagnosis of uterovesical fistula confirmed and patient planned for surgical repair of UVF. Laparotomy done. On per op examination the anterior surface of the uterus seen adherent to the bladder (Figure 1). Bladder dissected away from the uterus. A band seen between anterior surface of uterus and posterior wall of bladder. Further dissection done, and an opening seen in the posterior wall of bladder and anterior surface of uterus (Figure 2). The fistulous tract excised, and the opening of the uterus closed with vicrly No. 1 suture transversely. The urinary bladder closed in two layers with vicrly No. 2-0. Omental graft placed between the uterus and bladder. The abdomen closed in layers and per urethral catheter kept in situ for 2 weeks. Injectable antibiotics given for 5 days. Catheter removed on day 14 after proper bladder training.
Post-operative period was uneventful and patient discharged on day 15. Patient called for follow up after 4 weeks. Patient has resumed regular menstrual cycles and had no urinary complaints.

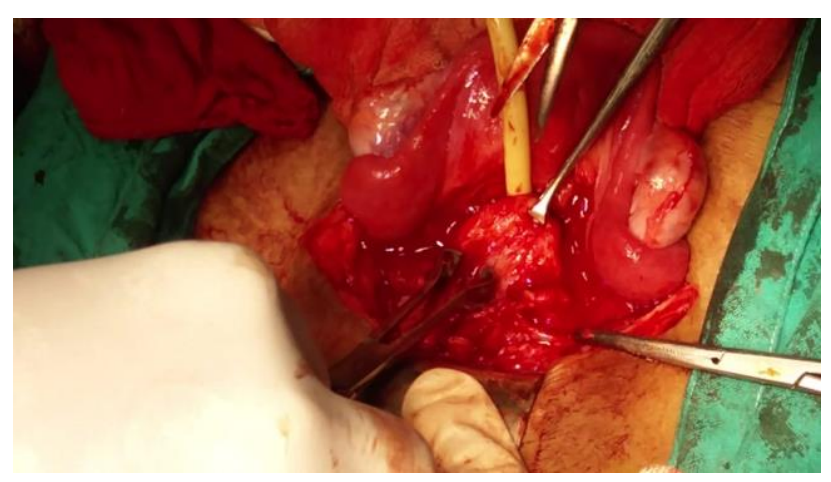

Figure 2: Vesicouterine fistula visualised during dissection.

\section{DISCUSSION}

Vesicouterine fistula is uncommon communication between the bladder and the uterus that usually occurs after iatrogenic injury especially during lower segment caesarean section. Its account for only 1-4 \% of all urogenital fistula. ${ }^{6}$ Youssef first reported VUF with classical triad of menouria, amenorrhoea and urinary incontinence it in 1957. ${ }^{7}$ Jozwik classified VUF into three categories based on menstrual flow: Type 1-with menouria, Type 2-with menouria and vaginal flow and Type 3-with normal menses. ${ }^{1}$ Lower segment caesarean section is commonest cause of VUF. ${ }^{8}$ It occurs due to inadequate mobilization of bladder during LSCS in case of deeply engaged head. It can also occur during instrumental delivery, myomectomy, rupture of uterus, during manual removal of placenta, brachytherapy in carcinoma cervix patient, dilatation and curettage and misplaced intrauterine contraceptive device. ${ }^{3}$ Spontaneous intrapartum VUF has also reported.

Various diagnostic procedures are available like methylene blue test, cystoscopy, retrograde cystography, hysterosalpingography; contrast enhanced computed tomography, and Magnetic resonance imaging (MRI).,9 MRI has now become the first choice in investigation fistulas. Treatment modalities for VUF are conservative management and surgical management. Conservative management is effective if fistula is small in size that is less that $0.5-1 \mathrm{~cm}$. It includes prolong catheterisation, antibiotics, anticholinergics, fulguration and induction of amenorrhea with hormones. Success rate in conservative treatment is less than $5 \% .^{3}$ Mainstay of treatment for large VUF is surgery. It VUF is diagnosed during surgery it should be repaired in same sitting otherwise it is recommended to postpone repair up to 3 months of causative surgery. Sometimes spontaneous closure occurs due to involution of uterus and with time inflammation is decrease as a result repair surgery become easy. Hysterectomy is not always necessary. ${ }^{1}$ Different 
approaches are there for surgical repair of VUF like vaginal, abdominal, laparoscopic and robot assisted laparoscopic repair. ${ }^{6}$ Hemal et al were the earliest to report robotic assisted laparoscopic repair of fistula. ${ }^{1,10}$ Omental graft is used during the repair of very big fistula as it act as a barrier between bladder and uterus and increase the rate of healing through better vascularisation. In present case, authors used transabdominal route to repair the fistula.

\section{CONCLUSION}

Although vesicouterine fistula are rare, it should be there in mind if patient present with a history of caesarean along with complain of haematuria and urinary incontinence. Identification of the anatomical landmarks and adequate retraction of the bladder during caesarean section helps in preventing these fistulae and its associated problems like psychological upset, social and physical problems.

Funding: No funding sources Conflict of interest: None declared

Ethical approval: Not required

\section{REFERENCES}

1. Nerli R, Patne P, Joshi K, Dixit N, Hiremath M. Vesicouterine fistula: a case report. J Sci Soc. 2015;42(1).

2. Ramamurthy $S$, Vijayan $P$, Rajendran $S$. Sonographic diagnosis of a uterovesical fistula. J Ultrasound Med. 2002;21:817-9.
3. Birge O, Ozbey EG, Erkan MM, Arslan D, Kayar I. Youssef's syndrome following cesarean section. Case Rep Obstet Gynecol. 2015;2015.

4. Ikechebelu JI, Ugboaja JO, Okeke CF. Post-cesarean vesicouterine fistula (Youssef syndrome): report of two cases. J Obstet Gynaecol Res. 2011;37(7):912-5.

5. Celdrán JO, Valverde FM. After Cesarean vesicouterine fistula (Youssef Syndrome) with successful conservative management. Urogynaecol. 2017;30(1).

6. Milani R, Cola A, Frigerio M, Manodoro S. Repair of a vesicouterine fistula following cesarean section. Int Urogynecol J. 2018;29(2):309-11.

7. Park OR, Kim TS, Kim HJ. Sonographic diagnosis of vesicouterine fistula. Ultrasound Obstet Gynecol. 2003;22:82-4.

8. Youssef AF. Menouria following lower segment cesarean section: a syndrome. Am J Obstet Gynecol. 1957;73:759.

9. Tancer ML. Vesicouterine fistula--a review. Obstet Gynecol Survey. 1986;41(12):743-53.

10. Chang-Jackson SC, Acholonu Jr UC, Nezhat FR. Robotic-assisted laparoscopic repair of a vesicouterine fistula. JSLS. 2011;15(3):339-42.

Cite this article as: Devkare V, Gothwal M, Gaikwad N, Pawar S, Agrawal N, Desai A. Youssef's syndrome following caesarean section: a rare case with review of literature. Int J Reprod Contracept Obstet Gynecol 2018;7:4772-4. 